\title{
In vivo 3D high resolution cardiac diffusion weighted MRI: a motion compensated diffusion-prepared balanced steady-state free precession approach
}

Christopher T Nguyen ${ }^{1,2^{*}}$, Zhaoyang Fan', Behzad Sharif ${ }^{1}$, Yi He$^{3}$, Rohan Dharmakumar ${ }^{1}$, Daniel S Berman ${ }^{1}$, Debiao $\mathrm{Li}^{1,2}$

From 17th Annual SCMR Scientific Sessions

New Orleans, LA, USA. 16-19 January 2014

\section{Background}

Cardiac diffusion-weighted MRI has the potential to identify acute myocardial infarction, myocarditis, and myocardial fibrosis [1-3]. The aim of this study was to implement and optimize a novel application of diffusion-prepared bSSFP to perform in vivo cardiac diffusion-weighted MRI.

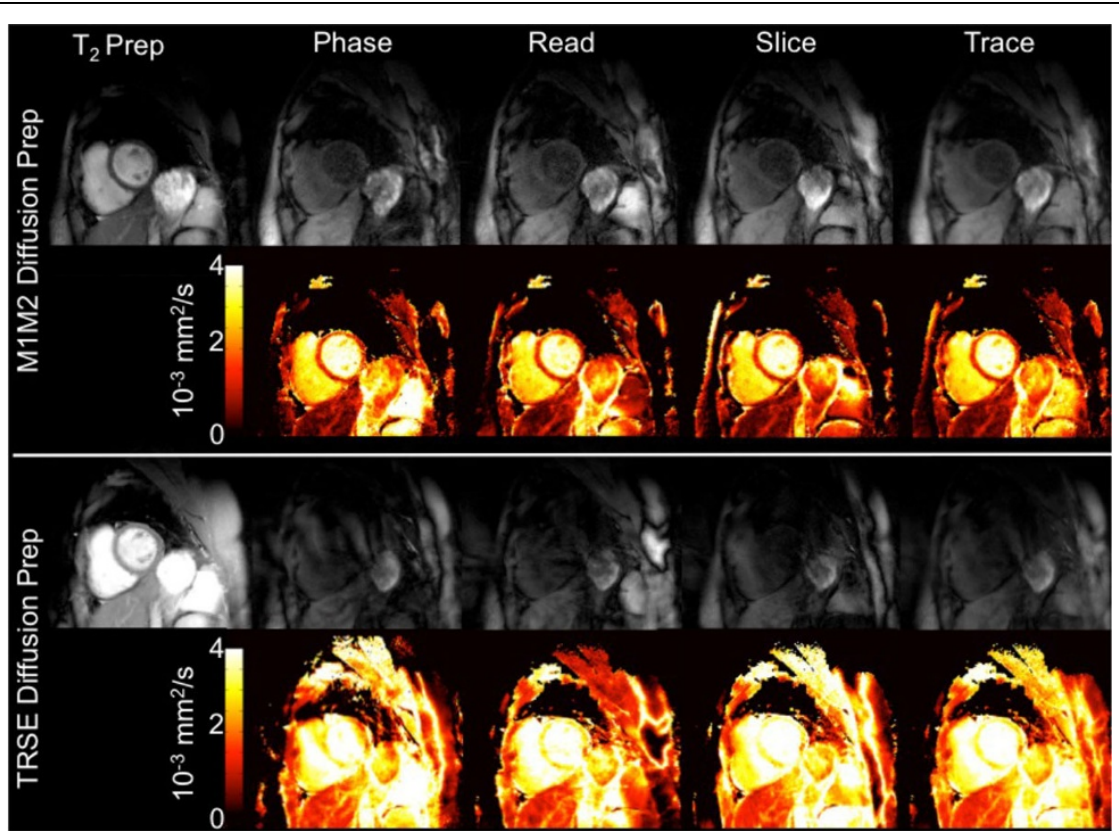

Figure 1 Typical T2 prepared $\left(b=0 \mathrm{~s} / \mathrm{mm}^{2}\right)$ images, DWI $\left(b=450 \mathrm{~s} / \mathrm{mm}^{2}\right)$ in three orthogonal directions, and ADC maps for M1M2 (top) and TRSE (bottom) diffusion preparation. M1M2 diffusion-prepared images clearly depict myocardium with minimal artifacts and yield reasonable myocardial trADC values. TRSE diffusion-prepared images present ghosting artifacts and signal drop out that are expected to arise in bulk motion corrupted diffusion-prepared sequences. LV trADC value derived from TRSE diffusion preparation are beyond diffusion of free water at $37^{\circ} \mathrm{C}\left(3.1 \times 10^{-3} \mathrm{~mm} / \mathrm{s}\right)$.

'Biomedical Imaging Research Institute, Cedars-Sinai Medical Center, Los

Angeles, California, USA

Full list of author information is available at the end of the article 


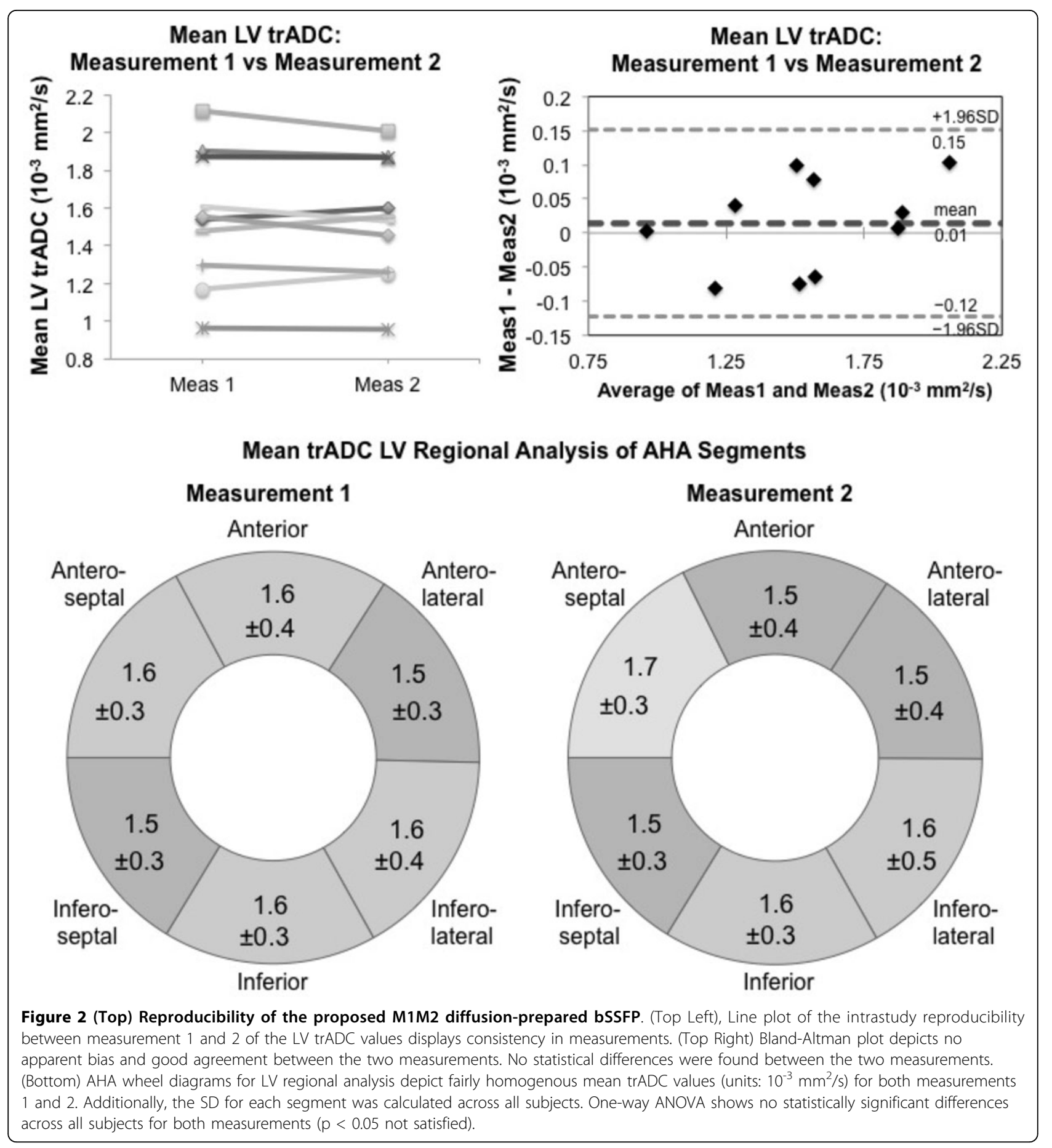

\section{Methods}

Diffusion-prepared sequences have the flexibility to diffusion encode with a multi-shot image readout. The diffusion preparation was optimized to reduce sensitivity to cardiac bulk motion with second order motion compensation (M1M2). The image readout consists of a 3D centric phase encoded segmented bSSFP acquisition that incorporates a prospective navigator. Ten healthy subjects were scanned twice (once in the beginning and at the end) on a $1.5 \mathrm{~T}$ system (Siemens Avanto) using the proposed technique $(\mathrm{TR} / \mathrm{TE}=3.4 / 1.3 \mathrm{~ms}, \mathrm{FOV}=256 \times$ $256 \mathrm{~mm}^{2}, \alpha=110^{\circ}, 160 \times 160$ matrix, $10 \mathrm{~mm}$ slice thickness, 4 slices with $20 \%$ oversampling, $40 \mathrm{~mm}$ 3D slab, 5 linear ramp-up, $\left.b=450 \mathrm{~s} / \mathrm{mm}^{2}, G_{\text {diff }}=40 \mathrm{mT} / \mathrm{m}\right)$. Diffusion preparation was applied in the diastolic phase with $($ TEprep $=115 \mathrm{~ms})$ and without $($ TEprep $=45 \mathrm{~ms})$ M1M2 
using 3 orthogonal directions under varying off-resonance conditions. Trace apparent diffusion coefficient (trADC) maps and the left ventricular (LV) trADC were calculated. For each slice, the LV was segmented into six AHA segments. Statistical significance was tested using two tailed paired $\mathrm{t}$-test for two mean comparisons and one-way ANOVA for multiple means comparisons.

\section{Results}

M1M2 diffusion-prepared scans resulted in LV trADC values of $1.5 \pm 0.4 \times 10^{-3} \mathrm{~mm}^{2} / \mathrm{s}$ that were reproducible yielding no statistical differences $(\mathrm{p}=0.54)$. Regional differences between six AHA segments were not statistically significant across all subjects $(p=0.97)$. M1M2 diffusion-prepared images showed no ghosting artifacts and/or signal fallout. Under certain substantial offresonance frequencies $(\mathrm{e} . \mathrm{g}+200 \mathrm{~Hz})$, the proposed method failed in yielding both T2prep and DW images when bSSFP-related banding formed. The non-motion compensated diffusion-prepared scans yielded LV trADC values of $6.6 \pm 0.9 \times 10^{-3} \mathrm{~mm}^{2} / \mathrm{s}$ and diffusionprepared images with severe bulk motion-induced artifacts.

\section{Conclusions}

The LV trADC values derived with M1M2 motion compensation diffusion preparation were consistent with previously reported values ranging from 0.8 to $2.4 \times$ $10^{-3} \mathrm{~mm}^{2} / \mathrm{s}$ [4-6]. The uncompensated diffusion preparation measurements yielded LV trADC values that were much greater suggesting motion corruption. We developed a novel free-breathing bulk motion compensated diffusion-prepared 3D segmented bSSFP technique able to perform in-vivo cardiac diffusion-weighted MRI on a clinical MR scanner.

\section{Funding}

NIH/NHLBI RO1 HL38698.

\section{Authors' details}

${ }^{1}$ Biomedical Imaging Research Institute, Cedars-Sinai Medical Center, Los Angeles, California, USA. ${ }^{2}$ Bioengineering, University of California Los

Angeles, Los Angeles, California, USA. ${ }^{3}$ Radiology, Anzhen, Beijing, China.

Published: 16 January 2014

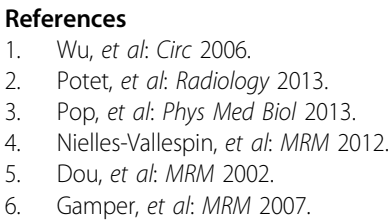

doi:10.1186/1532-429X-16-S1-083

Cite this article as: Nguyen et al:: In vivo 3D high resolution cardiac diffusion weighted MRI: a motion compensated diffusion-prepared balanced steady-state free precession approach. Journal of Cardiovascular Magnetic Resonance 2014 16(Suppl 1):O83.
Submit your next manuscript to BioMed Central and take full advantage of:

- Convenient online submission

- Thorough peer review

- No space constraints or color figure charges

- Immediate publication on acceptance

- Inclusion in PubMed, CAS, Scopus and Google Scholar

- Research which is freely available for redistribution

Submit your manuscript at www.biomedcentral.com/submit 